\title{
LA IDENTIDAD FEMENINA EN EL ESPACIO POLÍTICO: UN RECORRIDO SIMBÓLICO EN LA ECOLOGÍA DEL LENGUAJE
}

\author{
Dina Maria Martins Ferreira \\ dinaferreira@terra.com.br \\ Universidad Estadual del Ceará - Brasil
}

Recibido: 21-01-2016

Aceptado: 16-06-2016

\section{Resumen}

Este artículo discute la manifestación de lo femenino en proceso electoral brasileño. El discurso mediático nos da pistas que indican cómo lo femenino se convierte en instrumento político en un momento de decisión electoral. En dicho discurso se usan nominaciones simbólicas en juegos designativos, de tal forma que el símbolo no llega a consolidarse, sino que está al servicio del momento performativo. Las políticas de representación son constituidas paradójicamente: la naturaleza duradera del símbolo sirve al momento, los performativos se nutren de representaciones. El sistema simbólico, indicativo de cristalizaciones socioculturales, no se resiste a lo político del lenguaje y pasa a ser un recurso performativo de identidad de lo femenino.

Palabras Clave: Género, femenino, identidad, políticas, performativo, simbólicos, representación.

\begin{abstract}
This article debates the manifestation of the feminine in the electoral process in Brazil. The media discourse provides us with clues that indicate how the female becomes a political discourse in times of electoral decision. In such discourse, it's been used symbolic nominations in designative games. Nevertheless, it serves the performative moment. Politics of representation are being paradoxically made up: the lasting nature of the symbol serves the moment; the performative are nourished by representations. The symbolic system, indicating sociocultural crystallization, can't resist the politics of the language, and becomes a performative feature of the feminine identity.
\end{abstract}

Keywords: Gender, feminine, identity, politics, performative, symbolics, representation. 


\section{Introducción}

La revista Época, del 9 de septiembre de 2002, comprueba mediante pistas lingüísticas la presencia de lo femenino como instrumento decisorio para el futuro del país al proclamar en su portada que "La mujer decidirá la sucesión. Las primeras damas son estrellas en la recta final. El voto femenino es mayoría por primera vez" y es en el contexto de este movimiento político - Brasil, septiembre y octubre de 2002 - donde buscamos configurar el movimiento identitario de lo femenino construido por/en juegos designativos en el discurso de los medios.

Dado el alboroto surgido en torno a la figura de la mujer en la política, el corpus analítico se centrará en sujetos que aparecían asiduamente en los medios - revistas y diarios de circulación nacional - teniendo en cuenta que sus emergencias en el lenguaje estaban siempre condicionadas a movimientos de intereses políticos partidarios. A pesar de que el movimiento electoral del Brasil del 2002 se da por finalizado tras el triunfo de Lula como presidente, queremos dejar claro que no nos proponemos hacer un análisis de lo femenino resultante de determinado momento político, sino analizar el modo como los intereses políticos influyen y e incluso crean identidades. La cuestión no se limita a los hechos políticos en si, ni a si lo femenino gana o pierde en este proceso, sino a la articulación de juegos designativos y atributivos en la construcción de perfiles identitarios femeninos en un momento histórico.

Las ilustraciones nominativas girarán en torno a figuras femeninas, sea en pleno desempeño de sus cargos políticos, o acompañando a la figura masculina también en ejercicio político: la ex-precandidata a la presidencia de la república, Roseana Sarney; la candidata a la vicepresidencia del país por el partido de José Serra, Rita Camata; la candidata al gobierno del estado de Rio de Janeiro, Rosinha Garotinho; las esposas de los candidatos a la presidencia del país, Patricia Pillar (Ciro Gomes), Mónica Serra (José Serra) y Marisa Letícia Lula da Silva (Lula) y la alcaldesa de la ciudad de São Paulo, Marta Suplicy.

A pesar de especificar los nombres de las figuras femeninas muy divulgadas por los medios en aquel momento, lo que más nos interesa es la función valorativa desempeñada por lo femenino y no sólo el individuo que ocupa determinada función; la fuerza identitaria no está tanto en el espacio funcional sino en el modo en como el sujeto lo ocupa. Esto significa que nuestra propuesta de análisis no está vinculada a figuras específicas, sino que dichas figuras sirven a la configuración sociohistórica de lo femenino. Esta pretensión radica tanto en la representatividad de las funciones sociales como en la del discurso mediático, entendidos ambos como lugares de ricas referencias culturales dada su propia naturaleza colectiva que difunde múltiples valores y el imaginario colectivo. 


\subsection{Acerca del análisis}

La elección de ciertos fragmentos discursivos en detrimento de otros tiene por objeto atender a categorías femeninas que transitan en el sistema simbólico sociocultural brasileño. La naturaleza binaria de las categorías propuestas - feminidad y 'feminitud' - debe ser tomada nada más que como recurso metodológico que no pretende fijar presupuestos polarizantes. La feminidad se organiza en nominaciones que atienden a significaciones constitutivas de valoraciones patriarcales; este perfil de mujer-feminidad, aún cuando entendido como un punto de vista machista - se coincida o no con esta valoración -, todavía forma parte del imaginario popular, manifiesto en una cierta insistencia en el mantenimiento de una imagen femenina idealizada: mujer princesita, esposa-compañera protegida de los percances de la vida, mujer elegante y joven, señora distinguida, madre protectora y a disposición de las solicitudes del grupo familiar. La 'feminitud' ${ }^{1}$ es una categoría constituida por atributos que pueden distanciar la figura femenina del universo de la feminidad; es la mujer agente, activa que tiene una vida funcional, ya no dependiente y/o vinculada a lo falocrático, lo que no significa excluir ni la feminidad ni lo masculino.

\subsection{Acerca de la metología}

El recorrido argumentativo se construye a través de tres hilos que se van entrelazando a medida que se van tejiendo. Tal red busca dimensionar lo lingüístico como un nivel de manifestación posterior a cuestiones epistemológicas que problematizan el modo en como la 'naturaleza' del lenguaje se comporta en sistemas simbólicos.

Los fragmentos seleccionados para el análisis apunta a una metodología interpretativa y cualitativa. Este enfoque metodológico apunta a una metodología que se basa mientras progresa el análisis, con el fin de alcanzar el objetivo final: ¿cómo se comporta el lenguaje de la naturaleza simbólica, que, a su vez, se basa en la identidad femenina en contexto político.

En una investigación sobre una base cualitativa, estamos interesados, estamos interesados en la calidad de los datos analizados, mucho más que en la cantidad. Esto no quiere decir que no tenemos suficientes datos para apoyar la investigación, sino que el foco principal de trabajo cualitativo-interpretativo se produce en torno a un cuestionamiento alrededor del objeto para el que se propone estudiar, ya que "el investigador no es neutral, ni la ciencia es una actividad independiente de sociales, creencias y formas socialmente construidas de concebir el mundo, negado aspectos del paradigma positivista" (De Grande,

\footnotetext{
${ }^{1}$ Neologismo citado por Martins Ferreira, 2009: 105; se refiere a la mujer actual, moderna, que administra su mundo.
} 
2011: 12-13). A partir de esto, podemos estar de acuerdo con Fragoso, Recuero y Amaral (2011: 67):

"La investigación cualitativa tiene como objetivo un análisis en profundidad y la comprensión holística de los fenómenos en estudio y, por lo tanto, las descontextualiza y reconoce su carácter dinámico, sobre todo en la investigación social. En este contexto, el número de componentes de la muestra [leer: corpus] es menos importante que su relevancia para el problema de investigación, de manera que los elementos de la muestra se convierten deliberadamente seleccionados como proporcionar las características necesarias para la observación, la percepción y el análisis de las motivaciones principales de la investigación".

En línea con esto, a raíz de la idea de Patton (2002), lo que importa, en una encuesta de esta naturaleza es que los datos se presentan informativamente rico. Por lo tanto, podemos decir que se da prioridad a este trabajo, un enfoque en la discusión de los datos de un corpus que permitiría una discusión de un problema y más para dar prioridad a una cantidad razonable de datos para una enumeración que se convirtió en un patrón observable como que sería el caso de una búsqueda de naturaleza cuantitativa.

\section{El lenguaje y su naturaleza ecológica}

El primer escalón está en leer el juego designativo atribuido a la mujer a partir de la idea de que la lengua es ecológica ${ }^{2}$. Se entiende que el lenguaje tiene en su naturaleza la capacidad de re-significar en cada momento en que se materializa en lengua, dado que el lenguaje no excluye significaciones a lo largo de su recorrido en el espacio-tiempo histórico.

Al contrario, a cada expresión significante, residuos significativos se procesan y se remodalizan. Sería el caso de, por ejemplo al formular la frase 'Voy a ver la puesta de sol', en el momento actual, entrever la significación tolomaica de que el Sol gira alrededor de la Tierra y de que la Tierra es el centro de la galaxia, ya que estoy sentada, inmóvil en un espacio, viendo algo moverse a mi alrededor-soy el centro en relación a lo que se mueve. En una frase que tiene determinada significación como, por ejemplo, ver la puesta de sol en busca de tranquilidad luego de un dia agotador, se hallan residuos de otros significados transformados, incluso escondidos, pero no excluidos.

\footnotetext{
2 Término utilizado por el Prof. Dr. Kanavillil, Rajagopalan, en el salón de clases en el Curso de
} Pragmática, Pós-Graduação, IEL, Unicamp, segundo semestre de 2001. 


\section{El movimiento bustrofédico de la escritura y la ecología del lenguaje}

Se agregan a la primera etapa de la tesis temas de la filosofia derridiana que ayudan a armar la argumentación - el movimiento de la escritura ${ }^{3}$ :

"Se trata de la escritura por surcos. El surco es la línea, tal como la traza el labrador: la ruta - via rupta - cortada por la reja del arado. El surco de la agricultura, también lo recordamos, abre la naturaleza a la cultura y se sabe también que la escritura nace con la agricultura, que no se da sin la sedentarización” (Derrida, 1999: 351).

Derrida postula para la escritura un movimiento en bustrofédon ${ }^{4}$, o sea, un movimiento continuo, de izquierda a derecha y de derecha a izquierda, como el arado del buey al surcar el campo. Desde el punto de vista bustrofédico del lenguaje se constata que en este movimiento no hay interrupción, y esta continuidad permite reafirmar que el lenguaje es ecológico, o sea, es un proceso de continuo re-aprovechamiento en el que el vaivén del arado - lenguaje produce un des-velar de significaciones. Si el proceso de cultivo es continuo, a cada siembra de lenguaje los residuos remanentes de una antigua plantación se revuelven para agregarse a la siguiente. La tierra en la cual las designaciones son plantadas no logra eliminar y sustituir los trazos de antiguas plantaciones; es en el revolver del lenguaje-arado donde nuevos granos designativos se encuentran con residuos de otros granos que se remodalizan en nuevos juegos de lenguaje. Un momento histórico del lenguaje no elimina el anterior y no se excluye del posterior.

El movimiento en bustrofédon, realizado metafóricamente por el arado del buey, deja surcos y marcas, surcos profundos o no, según el instante histórico en el que son realizados, cuyas marcas culturales y sus significaciones puden ser re-descubiertas para más allá del momento de su arada, pues según la fuerza histórica del arado, los surcos sedimentados y cristalizados no se disuelven tan fácilmente:

“¿Cómo procede el labrador? Ahorrativamente. Al llegar al fin del surco, vuelve al punto de partida. Le da media vuelta al arado y al buey. Después, parte nuevamente, en sentido inverso. Ahorro de tiempo. De espacio y de energía. Mejoría del rendimiento y disminución del tiempo de trabajo. La escritura de vuelta del buey - bustrofédon -" (Derrida, 1999: 351-352).

\footnotetext{
${ }^{3}$ Valga enfatizar que estamos considerando la naturaleza de la escritura y no del lenguaje - phoné (cf. Derrida, 1999).

${ }^{4}$ Palabra de origen griego que significa al pie de la letra vuelta del buey, bous está para buey y strophe para giro; "giro de un renglón para otro, como hacen los bueyes al pasar de un surco para otro, o sea, escribiendo alternadamente de izquierda a derecha y luego de derecha a izquierda, manera de escribir usada en antiguas inscripciones griegas" (Machado, 1995: 477).
} 
El lenguaje entonces puede configurarse como un movimiento que surca su terreno (re)sembrando sus productos de significación y dejando residuos, pues su caminar es económico y su movimiento es ininterrumpido. Surcos presuponen marcas y trazos y la ecología tiene como característica fundamental el reaprovechamiento. El tejido metafórico permite pensar que el camino-surco con sus marcas es el hacer del lenguaje. El recorrido del lenguaje recibe los abonos de forma y contenido a cada espacio-tiempo recorrido, pues no se niega a las especificidades socioculturales de los juegos de lenguaje.

\section{Sistemas simbólicos en el camino ecológico y bustrofédico del lenguaje}

Si el caminar del lenguaje es ininterrumpido, atraviesa culturas revelando sistemas simbólicos que, por su propia naturaleza - símbolos, significaciones socioculturales que difícilmente se deshacen - no sufren cortes fronterizos entre si.

El momento de una significación nominada puede ser visto como una re-significación de otro significado marcado y surcado en otro momento espaciotemporal. En semiosis retrospectiva, como plantea nuestro trabajo, se recogen significaciones de momentos históricos que comparten propiedades sémicas constitutivas de sistemas simbólicos actuales y anteriores; y ante la hipótesis de una semiosis prospectiva, el movimiento ecológico es el mismo, se reactualizan significaciones provenientes de solidificaciones significativas de momentos designativos anteriores.

Lo que nos interesa es mostrar en la danza ecológica y bustrofédica del lenguaje cómo los sistemas simbólicos emergen en/por los juegos designativos, que a su vez configuran identidades de lo femenino. Se juntan ahí tres pilares analíticos - el ecológico, bustrofédico y el simbólico - que reflejan y se reflejan en los juegos designativos.

\subsection{Sistemas simbólicos: durabilidad y equivalencia de significaciones}

Al querer demostrar que la ecología del lenguaje y su recorrido bustrofédico permiten el roce entre sistemas simbólicos de momentos históricos diferentes - revolviendo los terrenos de la sincronía/diacronía -, no se está vinculando la idea del esencialismo al simbolismo, o sea, el simbolismo no refleja las esencias de los significados en la medida en que no se niega la morfología simbólica de cada cultura. Cada cultura es una caída en la historia, y como tal está circunscrita a un tiempo y un espacio propios. Lo que planteamos es la percepción de que

"Los símbolos son diversamente vividos y valorados: el producto de estas múltiples actualizaciones constituye en gran medida los 'estilos culturales' [...] (y) como 
formaciones históricas, estas culturas ya no son intercambiables; estando ya constituidas en sus propios estilos, puden ser comparadas en el nivel de las imágenes y los símbolos" (Eliade, 1996: 173) ${ }^{5}$.

El contacto entre culturas mediante el lenguaje estaría en su caráter ecológico que esparce residuos de significación por el camino bustrofédico de la escritura. El roce de culturas se ratifica por los residuos en el camino ininterrumpido, si tenemos en cuenta que símbolos son convenciones muy fuertes, cristalizaciones sociales, signos difíciles de desarmarse en el cansancio del recorrido histórico.

A medida que se entiende símbolo como cristalización y solidificación de significados culturales, el proceso de simbolización presupone la posibilidad de estabilizar los significados en detrimento de los significantes que se deslizan en instantes sociales. Valga como ejemplo en este recorrido argumentativo: una corona es lo que se pone sobre la cabeza de personas homenajeadas, líderes, nobles, reyes, reinas, en fin, es un objeto que indica que el sujeto que lo tiene sobre su cabeza es importante; no importa si tenemos en mente la época de los faraones, de los césares, de la nobleza europea en siglos áureos y actuales, reyes y emperadores; la corona simboliza, desde antes hasta ahora, por lo menos en el mundo occidental, la realeza, o sea, el estar-por-encima-de.

Los significantes cambian, pero el eje de la significación simbólica puede atravesar otros tiempos y espacios porque se atiene a la significación estar-por-encima-de. El movimiento simbólico se ancla en formas concretas, performatizadas a cada época, que se expanden abstractamente hacia el significado; por ejemplo, la corona de laureles de los césares, la corona de la Reina Isabel II de oro y piedras preciosas de formato triangular ovalado; morfologías específicas sobre las cabezas, cuyos significados históricos se expanden en la significación trans-histórica estar-por-encima-de.

Es en este sentido como se entienden los residuos de significación simbólica: son duraderos a lo largo de las aradas del lenguaje, dado que las significaciones de la vida cultural no se trituran y disuelven inmediatamente al paso del arado del buey, sino todo lo contrario. En este razonamiento metafórico, pero no menos lógico, se entienden símbolos como residuos duraderos de significación enclavados en los surcos, cuyas marcas profundas de expansiones significativas son recordadas en significantes adecuados a su contexto histórico; es en este 'recordar' del universo simbólico donde es posible percibir el contacto entre culturas.

Junto a la cuestión de la durabilidad del significado simbólico, la propia etimología del término símbolo ya ratifica la naturaleza ecológica y bustrofédica del lenguaje. La palabra griega súmbolon $($ de sun $=$ junto, con y ballein $=$ arrojar $)$ tiene el sentido de:

\footnotetext{
${ }^{5}$ Cursivas de la autora.
} 
“[...] 'lanzar con', arrojar al mismo tiempo, 'con-tirar'. Al principio, el símbolo era una señal de reconocimiento: un objeto dividido en dos partes, cuyo ajuste, cuya confrontación, permitía a los portadores de cada una de las partes reconocerse. El símbolo es, pues, la expresión de un concepto de equivalencia" (Brandão, 1986: 38)

Es justamente en los juegos designativos donde se establecen los juegos de equivalencia; equivalencias sémicas que se procesan entre el objeto nominado y los valores del sistema simbólico. La nominación provee el sistema simbólico como el significado de la nominación es provisto por el sistema simbólico. Cuando se nomina a una mujer como una mujer dama, se relaciona la figura femenina $x$ nominada dama con los posibles significados simbólicos instaurados y reconocidos por equivalencia con figuras femeninas $y$ estratificadas en el universo sociocultural. La nominación $x$ equivale a otras $y$ por el eje sémico - mujer fina, bonita, elegante, bien educada, noble ${ }^{7}$, superior al padrón común -, trazos que forman un universo simbólico, en el cual habitan femeninos de múltiples historias.

Al permitirse equivalencias de significado, el símbolo, viviendo en los surcos del lenguaje, no se inmoviliza en el tiempo y espacio en que se manifesta su naturaleza estable, mientras que la de jugar con significaciones en marcha bustrofédica permite que camine hacia otras historias sin anular las anteriores, rehaciendo en su arada continua otros modos de existencia. Los surcos construidos en bustrofédon abren ventanas para el trans-histórico de las simbologías. En este sentido, la nominación dama puede habitar una mujer política actual, Roseana Sarney o Marisa Lula da Silva, y la diosa griega Deméter, la dama del Hades.

En este caso, la figura del sujeto habita y performatiza el símbolo nominado. Este movimiento de la significación simbólica - ser habitada por una figura concreta - es un dato más para mostrar la cristalización del símbolo, ya que la convención significativa va siendo ocupada por figuras. Es la durabilidad del significado en busca de formas para emerger, es el significado buscando significantes; en fin, el significado antecede a la forma nominada. Plantearse que el significado antecede al significante está próximo a una de las propuestas de Derrida: existe un lenguaje mayor que antecede a nuestro lenguaje de significantes que lleva a significados y un juego de significantes explota con la rigidez del significado; no se está negando la propuesta tradicional, pero la estamos excluyendo de esta propuesta argumentativa.

Se ha caracterizado la naturaleza del símbolo mediante dos rasgos, durabilidad y equivalencia de significaciones: la durabilidad se muestra en la repetición de las concreciones históricas que se expanden en el abstracto trans-histórico de la significación y la equivalencia se presenta en la dimensión abstracta de los significados que anteceden a la forma. Ninguno

\footnotetext{
${ }^{6}$ Cursivas de la autora.

${ }^{7}$ No se está teniendo en cuenta otra posibilidad de significación de dama; en el norte del país el término dama también puede indicar meretriz, prostituta, pero con un uso específico, tal como en el ejemplo "ella es una mujer dama".
} 
de estos movimientos - concreto para abstracto y abstracto en busca de concreto - se hace más relevante que el otro, ninguno preexiste al otro, pues están en un continuo y complejo entrelazamiento. El orden dado al movimiento -durabilidad y equivalencia- es una mirada analítica que no determina su construcción. Concreto y abstracto, forma y contenido, figura y sujeto se constituyen como hilos de una red compleja, red que se configura en el mismo tejido de sus hilos. No existe red sin los hilos que la construyen. ¿Cuáles son sus reglas? Los juegos designativos las proveen en un entrecruzamiento sin fronteras, pues no hay punto de saturación en su entramado de significados, ni siquiera en lo simbólico, ya que "es situado y sensible a factores contingentes de coordenadas espaciotemporales que marcan su producción [...] es dispersión y diseminación en un interminable proceso" (Rajagopalan, s/d: 3).

\subsection{Juegos designativos en sistemas simbólicos}

Una vez descrito el recorrido de la escritura - lo ecológico que se ratifica en lo bustrofédico, lo cual permite mirar hacia sus sistemas simbólicos que emergen en juegos designativos -, el análisis se propone un trayecto inverso - de marcas lingüísticas en juegos designativos se llega a significaciones simbólicas, cuyos residuos son recogidos en el camino bustrofédico-ecológico del lenguaje. En este tejido, la dialética está en el des-bordar de juegos designativos de lo femenino, aquí sujetos políticos brasileños actuales.

\section{En Roseana Sarney...}

"La dama $^{8}$ de la sucesión. Hija de un ex-presidente, con salud frágil y un gobierno bien evaluado, Roseana Sarney se convierte en la estrella de la carrera hacia el Planalto al asumir el segundo lugar en las encuestas electorales" (Revista Veja, 14/11/200: 36) ${ }^{9}$,

...lo femenino es dama, estrella de un momento político, una mujer por encima del padrón, que tenía un porcentaje de votos populares muy alto; es la mujer femenina que también puede dirigir; es la feminidad, la mujer protegida, pues es hija del ex-presidente y tiene una salud frágil; el poder de la 'feminitud' no es negado, pero sólo se manifiesta mediante la feminidad; es un poder político que todavía no es activo.

Las nominaciones identitarias sobre la figura Rosinha (Rosa Matheus Garotinho) ya equiparan también feminidad con 'feminitud', pero son las nominaciones constitutivas de la feminidad las que introducen y llaman la atención hacia la práctica de la 'feminitud':

\footnotetext{
${ }^{8}$ El uso de cursiva en los fragmentos discursivos es de uso de la analista, como forma de llamar la atención para la categorización a ser analizada.

${ }^{9}$ Cursivas de la autora.
} 
"La fuerza de la garota ${ }^{10}$. Garotinho lidera. Por lo menos en Rio de Janeiro, con el nombre de Rosa. (Revista Veja, 04/09/2002: 44) [...] el brillo de Rosinha" (Revista Veja, 14/11/2002:45) [...] Rosinha Garotinho, en Rio, una primera dama de la que se tiene tan buen concepto que se transformó en candidata al gobierno con chances de ganar aún en la primera vuelta. Con un $45 \%$ de votos del electorado femenino, representa a la mujer exitosa, madre de nueve hijos - cinco de ellos adoptados - que no necesitó desapegarse del marido para tener éxito. La imagen de la mujer emancipada y acogedora es casi bíblica, afirma el lingüista Bruno Dallari [...] La mujer de Garotinho tiene personalidad fuerte. Ejerce tal poder sobre el marido que basta una discusión entre ambos para que él pierda el rumbo" (Revista Veja, 14/11/2002: 34) ${ }^{11}$.

Es joven al ser considerada una garota y en posesión de la juventud, brilla. Es madre, y más que madre, pues extiende sus brazos a nueve hijos, incluso los adoptados; por tal función es acogedora. Estas nominaciones la caracterizan como representante de la feminidad. Sin embargo, su personalidad fuerte le posibilita empezar a ejercer la 'feminitud', poder sobre el marido. Este camino le permite emanciparse y presentarse como candidata al gobierno de estado. El mismo juego de fuerzas entre feminidad y 'feminitud' se procesa en relación a Marta Suplicy:

"Bonita y conectada, la alcaldesa de São Paulo, Marta Suplicy, inflama los mítines de Lula. En los últimos dos meses, el rechazo al candidato entre las electoras descendió 2 puntos - y las intenciones de voto subieron 3 [...] la mujer combativa (del PT) está representada en las tribunas por Marta Suplicy [...]”. (Revista Época, 09/09/2002: 33) ${ }^{12}$.

En esta combinación de nominaciones, no se niega la figura femenina, pues es bonita, pero la 'feminitud' aparece en el juego político mediante las cualidades de conectada y combativa. 'Feminitud' y feminidad se solidarizan, ya que ambas categorías se presentan en el acto de inflamar, nominación que junta en su significado la emoción de la feminidad y la fuerza de la 'feminitud'.

El juego de fuerzas entre las categorías simbólicas de lo femenino sigue, pues tanto Rita Camata como Patricia Pillar, conocidas en los medios como mujeres que tienen carreras profesionales y son independentes - ésta, actriz de cine, teatro y televisión; aquélla, política y ahora candidata a la vicepresidencia de la República - trabajan y son, de algún modo, anuladas en/por la feminidad:

\footnotetext{
${ }^{10}$ N. de la T.: Garota(o): muchacha(o). Garotinho es el diminutivo de garoto y también el apellido de Anthony Garotinho, ex gobernador de Río de Janeiro y marido de Rosinha Matheus; de ahí que el periodista titule "La fuerza de la garota".

${ }^{11}$ Cursivas de la autora.

${ }^{12}$ Cursivas de la autora.
} 


\section{Rita Camata -}

- "En uma reunión de amigas. Rita reúne desde señoronas hasta feministas. Fue el martes, en la casa de Andréa Gouvea Vieira, el encuentro de Rita Camata con los llamados 'variados segmentos de la sociedad' del mundo femenino carioca. [...] Ahí una de las invitadas- partidaria férrea del PSDB - se apropió de dos expresiones de Rita Camata en su discurso y declaró: 'yo, como mujer a nivel de mujer, preferiría estar en un shopping"” (Folha de São Paulo, 12/07/2002: A6) ${ }^{13}$;

- "Propuesta indecente. El petista José Genoíno no perdió tiempo al ver su colega Rita Camata (PMDB) en la Cámara. "Ven para el PT. Estás en el lugar equivocado" (Folha de São Paulo, 12/06/2002:A10) ${ }^{14}$.

\section{Patricia Pillar -}

- "La actriz Patricia Pillar retribuye al cariño del público, al lado de Ciro Gomes [...] Patricia se convierte en la estrella del evento de Ciro" (Folha de São Paulo, 20/07/2002: A6) ${ }^{15}$;

- "Floreos y aplausos. Considerada un as en la manga de la candidatura del novio, la actriz desempeñó, en el evento, el papel de presentadora" (Folha de São Paulo, 22/06/02: A1) ${ }^{16}$; - "Brazo fuerte. Patricia Pillar es cada vez más influyente en la campaña de Ciro Gomes.

[...] En el debate entre los candidatos a la presidencia, fue la única aspirante a primera dama a acceder al lugar reservado a los principales asesores de campaña. [...] "Fuera de los bastidores, la actriz apuesta por los planes del marido su bien más importante: la imagen construida en años de carrera discreta y empeñada en interpretar personajes positivos, con función social transformadora [...] Patricia garantiza un cierto tono comprometido y ético a la campaña [...] 'Mi compañera tiene uno de los papeles más importantes, que es el de dormir conmigo. Dormir conmigo es un papel fundamental"' (Revista Época, 09/09/2002: $32)^{17}$.

Rita Camata muda el perfil del cargo de candidata a la vicepresidencia, pues su función se establece en una reunión de amigas, en la que reúne desde señoronas hasta feministas, para decir que le gustaría estar en un shopping, lo cual indica que su papel preferido es el consumo y no lo político. Es la figura femenina que puede ser comprada por lo masculino mediante una propuesta indecente, en alusión a la película americana "Propuesta Indecente", muy popular en su momento por la presencia de artistas famosos, en la cual, con la connivencia del marido, una mujer casada (Demi Moore) cede ante la propuesta por parte de un millonario enamorado (Robert Redford) de pasar una noche de amor, por un millón de dólares. Es el caso de una mujer

\footnotetext{
${ }^{13}$ Cursivas de la autora.

${ }^{14}$ Cursivas de la autora.

${ }^{15}$ Cursivas de la autora.

${ }^{16}$ Cursivas de la autora.

${ }^{17}$ Cursivas de la autora.
} 
sin fuerzas que cede ante las circunstancias. El grado de feminidad, bajo una perspectiva falocrática, es sarcástico, indicando con ironía el verdadero papel de la mujer. En este caso ni siquiera se presenta la 'feminitud', sólo resta una mirada ideológica de burla a la feminidad.

Por el contratrio, Patricia Pillar aparece nominada con una 'feminitud' madura: discreta y empeñada, tono comprometido y ético; una dinámica que muestra que su figura es un as en la manga en la campaña de su marido. Es la mujer activa, independiente, pero a la vez es compañera, pues apuesta por los planes del marido. Surgiría un embate que difícilmente tendería hacia uno de los lados; sin embargo, lo masculino reduce la figura ideal de lo femenino, según los medios, a luchadora y a compañera. Ella pasa a ser importante porque $s u$ papel fundamental es el de dormir conmigo. La mujer placer anula a la mujer hacer. El sarcasmo nuevamente destruye los laureles de la 'feminitud'.

Sin embargo, la disputa de valores no siempre se establece. En el caso de Mónica Serra, esposa del candidato a la presidencia de la república por el partido del gobierno, las categorías parecen encubiertas:

"Por el temperamento discreto y por la biografia académica, la psicoterapeuta Sylvia Mónica Allende Serra recuerda a Ruth Cardoso, la única primera dama brasileña con carrera profesional desapegada de la del marido. [...] A los 58 años, dos hijos, un nieto en gestación, con un fuerte acento chileno, Mónica es una de 'aquellas mujeres multimedios, difíciles de clasificarse" (Revista Época, 2002: 31) ${ }^{18}$.

La descripción tanto de la "feminitud" (académica, psicoterapeuta, desapegada) como de la feminidad (madre de dos hijos y abuela de un nieto en gestación), dificulta la emergencia de un perfil identitario preciso según las convenciones; es una mujer de multimedios, difícil de ser clasificada dentro de límites claros. La única figura que no esconde, porque parece no tener 'feminitud', es Marisa Lula; no existen tensiones en las nominaciones que se le atribuyen:

"A los 52 años, Marisa Letícia Lula da Silva vive la cuarta elección presidencial de su marido - pero por primera vez participa activamente. Apareció más delgada en las tribunas, con una expresión suavizada por el lifting, el corte de pelo de Wanderley Nunes, el mismo peluquero de Gisele Bündchen. Cuando está al lado de Marta Suplicy, parecen hermanas. [...] Tenía la cabeza en su casa, en el hijo benjamín de 17 años que anda con una alergia en la piel diagnosticada por un médico como 'mamitis' [...] Marisa grabó una declaración para el programa partidario, reformuló la imagen y se fue a las tribunas [...] Preparada para mostrar el lado familiar del marido en la campaña [...] A Marisa lo que realmente le gusta es andar descalza, embutida en su mono, con un sombrero de paja en la cabeza, tratando a los cabritos, gallinas, conejos, faisanes y pavos en el criadero de su finca en los alrededores de São Bernardo do Campo [...] Ser primera dama nunca ha sido

\footnotetext{
${ }^{18}$ Cursivas de la autora.
} 
su aspiración en la vida. Ella ya ha anunciado que, si Lula sale elegido, cumplirá todos los protocolos, pero siempre que le sea posible pasará por su casa para echarle un vistazo a la vida doméstica" (Revista Época, 09/09/2002: 33) ${ }^{19}$.

Marisa es la figura femenina modelada en la feminidad para atender a los objetivos políticos de aquel momento, que por juegos designativos da un tono de euforia al camino político del marido (Lula - actual presidente de Brasil), padre, que tiene una vida doméstica estándar. Marisa desliza su significante feminidad por la vanidad y los cuidados con su apariencia (lifting, pelo corto), por su papel de madre (mamitis), por su cargo de ama de casa (andar-descalza, embutida en su mono, sombrero de paja, echarle un vistazo a la vida doméstica). Lo femenino se instaló en un escalón simbólico como un modo de contribuir a que el sujeto masculino alcance su objeto de deseo, ella es adjuvante del proyecto de realización del otro. El sistema patriarcal vigora incólume por el deslizar suave de la feminidad.

\section{La política de la representación identitaria de lo femenino}

El tejido analítico de lo femenino ha echado mano de dos categorías que atienden al sistema simbólico: por un lado la mujer suave y compañera de lo masculino y, por otro, la mujer agente. Sin duda, no se niega que el perfil identitario "sólo existe cuando se lo denomina, y el mundo de los significados no es otro sino el del lenguaje" (Barthes, 1989: 12). Pero si cambiáramos el término existe por se manifiesta, atenderemos con más maleabilidad a la cuestión de la política de la representación y no sólo a la representación en si, ya que ésta podría presuponer una entrada en el esencialismo de la carga simbólica de las categorías feminidad y 'feminitud'. La identidad es "un constructo y no algo que se encuentra por ahí in natura" (Rajagopalan, 2002: 77), tanto que las categorías feminidad y 'feminitud' pueden representar una cuestión de política de la representación de lo femenino, "afirmada y reivindicada" (Rajagopalan, 2002: 86) por intereses políticos de un Brasil electoralista en el 2002.

En el corpus, la actuación discursiva de estas simbologías ya identifica la no rigidez de esos valores, pues al transitar entre si constituyen performativos que configuran movimientos contra la hegemonía de una de estas categorías como un centro que identifica a lo femenino. La figura de Marta Suplicy es nominada como bonita y conectada, valoraciones que amalgaman en un único sujeto significaciones simbólicas diferentes, bonita que categoriza la feminidad y conectada a la 'feminitud'. En el plano de la acción social, Mónica Serra está desapegada del marido; la independencia femenina se reafirma por la nominación desapegada. Sin embargo, la idea de desapegar presupone la idea de pegado; además, un papel no anula el otro, pues la función "mujer de" no excluye el desempeño profesional como académica; no es posible

\footnotetext{
${ }^{19}$ Cursivas de la autora.
} 
desapegar un dato que forma parte de la anatomía de su identidad: Mónica Serra está pegada al marido en su papel de esposa. El contorno identitario no es limítrofe. El juego nominativo, que contrapone o une categorías, tanto en la dimensión discursiva como en la social, es el juego de la presencia del Otro en la creación de una nueva identidad a ser destacada: "La importancia de identificar a un Otro para, en seguida, demonizarlo como condición esencial para darse a sí mismo una nueva identidad y una nueva razón de ser fue destacada" (Rajagopalan, 2002: 84). Es el caso de un marido machista que demoniza la 'feminitud' en pro de la feminidad, o de una demonización sobre la feminidad para destacar el desempeño 'feminitud' de lo femenino en un cargo de comando; la presencia del Otro, demonizado o abrazado, es un juego político para evidenciar una nueva identidad.

Representar lo femenino por valencias categoriales no significa pensar la representatividad como inmutabilidad y rigidez de valores en la constitución de la identidad, ya que no se niega el proceso performativo de su constructo. Lo que sí puede ser inmutable es el momento de reconocimiento de una significación simbólica almacenada ecológico-bustrofédicamente en el imaginario colectivo. El reconocimiento ya es un performativo y como tal sigue su proceso natural de manifestarse en los múltiples instantes de los juegos del lenguaje.

\section{Conclusiones}

En los juegos de lenguaje las categorías de evaluación, utilizadas en nuestro análisis para la constitución de la identidad femenina - feminidad y 'feminilitud' -, van modelando la figura de la mujer de acuerdo a los intereses de un tiempo electoralista político. Y en este modelo, incluso si la hembra es impulsado por los estereotipos despectivos, las figuras femeninas son, sin embargo, necesaria para la eficacia del juego político en el que se generó.

En los argumentos analíticos presentados, se concluye que el perfil femenino oscila de acuerdo con la política de representación requerida por el momento histórico con sus metas ideológicas y políticas. Los valores culturales emergen según los intereses políticos y la transformación histórica, ya que es a través de la representación como las nuevas identidades son constantemente reivindicadas.

Se ratifica el carácter político en el manejo de los símbolos, que, a pesar de sus significaciones cristalizadas de lo cultural cargadas de resíduos de su camino ecológicobrutofédico, no dejan de mostrar los intereses pragmático-políticos. Como la naturaleza cristalizadora del símbolo no se fija, ya que el símbolo es un instrumento performativo, se instaura una paradoja: lo duradero sirve al instante, se vuelve instante una vez que nomina algo para un fin político, es decir, la representación duradera se nutre de performativos del instante, creando nuevas representaciones. El sistema simbólico, indicativo de cristalizaciones socioculturales, no se resiste a lo político del lenguaje, pasa a ser un recurso performativo de 
identidad de lo femenino. El lenguaje, aunque se manifieste en el y por el sistema simbólico, es político; es el espacio en el cual se constituye la identidad femenina. Sin embargo, no podemos dejar de pleiterar que el problema de la identidad construida por los juegos designadores va más allá de la política, porque el ser humano, a pesar de expresarse en el lenguaje, también es como tal por su praxis social.

\section{BIBLIOGRAFÍA}

- Barthes, Rolan (1989): Elementos de Semiologia (Elementos de la Semiótica). Tradução Júlio Castañon Guimarães. São Paulo: Cultrix.

- Brandão, Junito de Souza (1986): Mitologia Grega, Volume I. (Mitología Griega, Volumen 1), $2^{\text {a }}$ Ed. Rio de Janeiro: Vozes.

- De Grande, Paula Baracat (2011): “O pesquisador interpretativo e a postura ética em pesquisas em Linguística Aplicada" (El investigador interpretativo y ética en la investigación en Lingüística Aplicada). En: Eletras, vol. 23, $\mathrm{n}^{\circ}$. 23, pp. 11-27, [en línea] Disponible en: www.utp.br/eletras [21/12/2015].

- Derrida, Jacques (1999): Gramatologia (Gramatología). Tradução Miriam Schnaiderman e Renato Janine Ribeiro. $2^{\mathrm{a}}$ Ed. São Paulo: Editora Perspectiva.

- Eliade, Mircea (1996): Imagens e Símbolos (Imagénes y Símbolos). Tradução Rogério Fernandes. São Paulo: Martins Fontes.

- Machado, José Pedro (1995): Dicionário Etimológico da Língua Portuguesa (Diccionario Etimológico de la Lengua Portuguesa). Lisboa: Horizonte.

- Martins Ferreira, Dina Maria (2009): Discurso Feminino e Identidade Social (Discurso femenino y la identidad social). $2^{\text {a }}$ Ed. São Paulo: FAPESP/Annablume.

- Patton, Michael (2002): Qualitative Research and Evaluation Methods. $3^{\mathrm{a}}$ Ed. London: Sage.

- Votre, Sebastião J. (2002): “Linguagem, identidade, representação, imaginação” (Lenguaje, Identidad, Representación, Imaginación). En: Lucia M.A. Ferreira y Evelyn G.D. Orrico (org.): Linguagem, Identidade e Memória Social (Linguaje, Identidad e Memoria Social). Rio de Janeiro: UNI-RIO, FAPERJ, DP\&A Editora, p. 89-107.

- Rajagopalan, Kanavillil (2002): "A construção de identidades e a política de representação" (La construcción de las identidades y las políticas de representación). En: Lucia M.A. Ferreira y Evelyn, G. D. Orrico (org.): Linguagem, Identidade e Memória Social (Lenguaje, Identidade e Memoria Social). Rio de Janeiro: UNI-RIO, FAPERJ, DP\&A Editora, p.77-88.

. (n.d): The world as a stage magic realism and the politics of representation (El mundo como un realismo mágico escenario y las políticas de representación). CNPq no 306151/88-0, mimeo.

- Rorty, Richard (1995): Contingência, ironia e solidariedade (Contingencia, ironía y solidaridad). Tradução Nuno Ferreira da Fonseca. Lisboa: Presença. 